\title{
A Content Analysis of Gender Bias in When English Rings A Bell Textbooks
}

\author{
Lisa Julianti \\ Universitas Tanjungpura \\ lisajulianti@ymail.com \\ Ikhsanudin \\ Universitas Tanjungpura \\ ikhsanudin@fkip.untan.ac.id \\ Gatot Sutapa \\ Universitas Tanjungpura \\ yohanes.gatot.sutapa.y@fkip.untan.ac.id
}

\begin{abstract}
This thesis reports on the gender bias contained in English e-textbook for junior high school students provided by the ministry of education. The study used a framework proposed by Porreca (1984) as guidance. The framework is distinctive because it examines the problem of gender representation contained in textbook. Based on the framework the study focused on gender visibility in text and illustration, gender firstness, occupational role, gender neutral nouns and gender specific nouns, masculine generic construction, and adjectives. The finding reveals that although there is an effort to avoid gender bias, females are still represented traditionally in some categories. When females are portrayed traditionally in the textbook, students develop a stereotype view towards female students.
\end{abstract}

\section{Keywords: Gender Bias, Textbook Analysis, Gender Representation}

\section{INTRODUCTION}

A textbook is a medium in which learning material is provided in such a way that both teacher and learner can use it in order to support the teaching and learning process. Furthermore, textbooks are often the only if not the main sources of learning in Indonesia (Ena, 2013; Sardjunani, 2013). For this reason, textbook must be selected based on some consideration in the analysis step. One way from which a textbook can be analyzed is the representation of males and females.

The way males and females are portrayed in a textbook can affect how students perceive the social role that is assigned to male and female. Sunderland (1992) asserts that course books' representations of gender potentially affect students as language learners and users. For example when a textbook portray woman as merely housewife, it may cause female students to think that being a housewife is the only role they can do in real life.

In practical, teachers might teach students with gender bias unintentionally. Teachers with their routine duty regarding preparing teaching materials and classroom management have limited time to analyze and reflect on their teaching activity and interactions with students. For this reason, many teachers do not believe gender inequity to be a problem in their classrooms. 
Messages, however unintentional, sent by teachers during middle school could have a lasting effect on self-concept and selection of future academic goals (Slater, 2003). Thus, teacher must aware that the role of curriculum including the textbooks they use is critical to ensuring that boys and girls are given equal opportunities for success and advancement in schools (Sardjunani, 2013). Gender bias in school can take place unintentionally practiced by teacher. For example when in a discussion, male students are more demanding, shouting out answers in a manner that is difficult to ignore (Slater, 2003).

There are many categories we use in everyday life that help us in deciding how we behave toward people. But gender has certain reason to be a concern. This is because gender is embedded so thoroughly in our institutes, our actions, our beliefs, and our desires, that it appears to us to be completely natural (Eckert \& Ginet, 2003, p. 9; Jin, Ling, Tong, Ling, \& Tarmizi, 2013). When we categorize people into certain features that belong to particular group meaning we make stereotype about that people. Stereotype can be positive or negative, thus our stereotype toward certain people affect our behavior toward them.

Based on Permendiknas No. 2 Tahun 2008 educators can select textbook considering the quality and its compliance to the Indonesia's National Agency for Education Standards. For the present study the textbooks selected are junior high school English textbooks because English was chosen as a compulsory foreign language to learn starting at the junior high school level (Ena, 2013, p. 24).The textbooks are "When English Rings A Bell" for grade VII and "When English Rings A Bell" for grade VIII. The textbooks are e-textbook which were published by the Ministry of Education. They are uploaded to the internet, thus an internet connection is needed in order to be able to download or read.

One of the approaches in textbook analysis is through content analysis. The using of content analysis can reveal how the contents of virtually any type of communication have been presented (Fraenkel, Wallen, \& Hyun, 2012). The present research will investigate how the textbook present value in society based on gender representation. We need to be able to examine the implications that use of a set of materials may have for classroom work and thus come to grounded opinions about whether or not the methodology and content of the materials is appropriate for a particular teaching context (Littlejohn, 1998).

This study aims at analyzing the representative of males and females in the textbooks. Furthermore, it seeks how males and females are portrayed in the textbooks and are there any stereotypes which embedded to certain gender. Since such stereotypes are unearth they can be taken into account in evaluating material for future use, or if the material is already in use they can be identified, confronted and discussed openly with students (Cunningsworth, 1995, p. 91).

\section{METHOD}

Based on the research questions aforementioned, this study uses content analysis. Content analysis is a technique that enables researchers to study human behavior in an indirect way, through an analysis of their communication. Textbooks, essays, newspapers, novels, magazine articles, cookbooks, songs, political speeches, advertisement, pictures - in fact, the content of virtually any type of communication - can be analyzed (Fraenkel, et al., 2012).

The study is conducted based on Porecca's (1984) framework. The illustration and activities are analyzed for visibility, gender firstness, gender neutral and specific noun, occupational role, masculine generic construction, and adjectives used with females and males. To explore the meaning underlying counted data, a qualitative approach was applied. Qualitative content analysis is an approach of empirical, methodological controlled analysis of texts within their context of communication (Mayring, 2000). Furthermore, Mayring (2000) asserts that qualitative content analysis preserves the advantages of quantitative content analysis for a more qualitative text interpretation. Some of those advantages are to determine the situation of text production, the text itself, or the effect of the message. Besides elaborating the study in qualitative approach, quantification is also applied as a means of making available techniques which add power and 
sensitivity to individual judgment when one attempts to detect and describe patterning in a set of observation (Miles \& Huberman, 1994, p. 41).

Since this study works with prior theory of gender representation particularly from the work of Porreca (1984) then it uses deductive approach. Deductive approach works with prior formulated, theoretical derived aspects of analysis, bringing them in connection with the text (Mayring, 2000).

The Data

The data is collected from textbooks entitled "When English Rings a Bell" for grade VII and VIII. Those books are selected because they are recommended by the Ministry of Education to be used in schools. The textbooks are provided online so that teachers and students can download it independently. The textbooks consist of eleven chapters and twelve chapters, respectively. Each chapter consists of activities which have different purposes. The data is taken from both text and image.

Instrument

The instrument is designed based on the data to be taken. Some data require an observational sheet while some others require an observational checklist. For research question number 1, the instrument is an observational sheet which contains rows to put the frequency of male and female visibility in each chapter. For research question number 2 , the instrument is an observational checklist which contains rows for each activity, male and female to reveal how many female and male appear first in each chapter.

For research question number 3 , the instrument is two types of observational sheets they are for gender neutral noun and gender specific noun. The first observational sheet is for gender neutral noun, first of all, the neutral nouns are tallied, and then they are put into the observational sheet as column headings. This instrument is to reveal how many neutral nouns are used for each chapter and what nouns they are. The second is an observational sheet for gender specific noun. First of all, the specific nouns are tallied, and then put into the observational sheet as row headings. This instrument is to reveal how many specific nouns used to refer to female and male, and what nouns they are.

For research question number 4, an observational sheet is used to reveal occupational role designated to certain gender. First of all, occupation designated to male/ female are tallied, and then put into the observational sheet as column headings. Gender roles are also noted down into the observational sheet to reveal what role each gender is represented in each textbook. For research question number 5, an observational sheet is used to record the usage of masculine generic construction in sentences. For research question number 6, an observational sheet is used to reveal adjectives used with female and male.

\section{Procedure}

Philipp Mayring (2000) proposed to design a coding agenda in a deductive/ direct approach. In coding agenda, category definition, prototypical text passage, and rules for distinguishing different categories are formulated in respect to theory and material, are completed step by step, and are revised with the process of analysis. Thus, the procedure of this content analysis is as follows.

First, in terms of visibility, the number of occurrence of males and females in texts and illustrations was counted. The occurrence in text limited to name given to a character. Since, simple ratios reveal only quantities and cannot reveal the ways in which males and females are presented (Porreca, 1984). Therefore it will be illuminating to discover how males and females presented in the textbooks. For example: there are no women presented in particular chapter or there are reading texts, exercises, or illustrations in particular chapter present women in negative ways.

The second data is gender firstness - the number of times that males or females are presented first in exercises, examples, or sentences - was tallied. Porreca (1984) asserts that when masculine words mostly come first, it reflects the second-place status of women. The order of appearance refers to a widespread belief in almost every society that men are very important rather than women thus, it is obligatory to put them first everywhere (Hameed, 2014, p. 110). Since the textbooks mostly contain illustration and the book sections are divided into activities, thus, the data taken in terms of gender firstness is specifically every gender illustrations which appear first in each activity. 
Third, gender neutral and gender specific noun was counted. The more frequent usage of a specific gender in the texts will portray dominance or favoritism towards the particular gender, especially the males (Jin, et al., 2013, p. 18).

Forth, occupational role and gender role was noted. Every time an occupation and role which certain gender represented is mentioned, it is noted down in an observational sheet designed previously with two categories; male and female.

Fifth, every text which used male noun to present both male and female is noted down to reveal whether or not it still used masculine generic construction.

Sixth, adjectives which are used with certain gender is noted down in an observational sheet to reveal whether or not there is gender stereotypes represented with adjectives.

Data Analysis

Certain tactics for generating meaning proposed by Miles and Huberman (1994) is used to guide the qualitative analysis process. There are 13 specific tactics for drawing meaning from a particular configuration of data in a display (Miles \& Huberman, 1994, p. 245), but only five of the tactics which are relevant for the present study. The tactics are: noting patterns, counting, making contrast/comparison, subsuming particulars into the general, and noting relations between variables. Noting patterns: noting the pattern of variables involving similarities and differences among categories (Miles \& Huberman, 1994, p. 246); counting: gaining frequency (Miles \& Huberman, 1994, p. 253) is used in order to minimize any bias; making contrast/ comparison: we draw a contrast or make a comparison between two sets of things, person, roles, activities, cases as a whole - that are known to differ in some other important aspects (Miles \& Huberman, 1994, p. 254); subsuming particulars into the general: locating the immediate act, event, actor, or activity in a more abstractly defined class. For example a specific thing is an instance of a certain category (Miles \& Huberman, 1994, p. 255); noting relations between variables: discover what sort of relationship - if any between two (or more) variables (Miles \& Huberman, 1994, p. 258).

The analysis of each category requires certain tactics for generating meaning. In terms of visibility, counting tactic will illuminate the importance of certain gender. Visibility involves names used designated to certain gender and illustrations portraying certain gender. Name is text and illustration is picture or image. Textbooks contain more visual image than written text, they can articulate more forcefully social and cultural meaning (Hamid, Yasin, Othman, Bakar, Hashim, et al., 2012, p. 154). Thus, when certain gender is used more frequently in illustration it implies that certain gender is more important than the other.

Gender firstness requires counting tactic in the analysis. The frequency of female and male first occurrence reveals the importance of certain gender. If male dominantly occur first, it implies that female occupies second-place in the textbook. Since the textbook contain major portion of image, then the analysis of gender firstness is confined to image.

Gender neutral noun and gender specific noun is analyzed with counting, making contrast/comparison, and noting relation between the nouns with other characters. The frequency of each noun is used to confirm the accuracy of the initial analysis. The more frequent usage of a specific gender in the text will portray dominance or favoritism towards the particular gender, especially male (Jin, et al., 2013, p. 117). The frequency aids in making contrast/ comparison for instance; the noun mother is used more often compared to the noun father. The relationship between variables for instance the noun father is used frequently with the noun son.

The occupational roles assigned to male and female will reveal how the textbook represent women. Tactics of noting pattern, counting, and subsuming particulars to the general are used for this category. Similarities or differences in occupational role are noted, frequency of certain occupation designated to certain gender is counted, and the occupation of both genders is associated to a larger group of occupation level for instance inferior and superior jobs.

The use of masculine generic construction is counted reveals if there is still tendency towards certain gender in the textbook. The adjectives used designated to females and males reveal how both genders are represented in the textbooks. The tactic used for this category is noting pattern. 


\section{RESULTS AND DISCUSSIONS}

\section{Results}

Visibility

The main characters in the textbooks remain the same from the beginning until the end of the books. The characters are introduced in the first chapter. They are Beni, Udin, Lina, Edo, Dayu, Siti, a female teacher and a male teacher. Beni, Udin, and Edo are designated to male students, while Lina, Dayu, and Siti are designated to female students. One teacher is portrayed as female and one teacher is portrayed as male. From the characters it is clear that the writers are avoiding imbalance gender characters. Males as well as female are portrayed 5 characters each.

In visibility, there are two categories taken as the data. The first is male and female characters in illustration and male and female characters in text (name designated to certain gender). Thus, once an illustration of male or female occurs, it is noted in the cell of observation list. Once a name as aforementioned above is mentioned, it is noted in the observation list.

It was found that in both textbooks female characters in text outnumber male characters. Meanwhile, male characters in illustration outnumber female characters. In "Werab VII" chapter three the illustration of male outnumber female characters significantly; males occur 74 times or 8.4 $\%$ of total illustration occurrences, while females occur 41 times or $4.6 \%$ of total illustration occurrences. Consequently, male characters occur more often than female characters in this chapter.

In total, the percentage of males character also occur more often than female characters; males $54 \%$ and female $46 \%$. When male characters are represented more often visible than female characters students are led to believe that males are the norm, the standard in the society (Hamid, Yasin, Bakar, Keong, \& Jalaludin, 2008, p. 54).

The first research question was: How is gender representation in the illustration and texts? Both textbooks reveal that males are dominantly portrayed in illustration which might cause reader to interpret that male is more important and female is less important. The undervaluing of women potentially adds to the female language learners sense of alienation and worthlessness, making adjustments more problematic and perhaps slower than for her male counterpart (Al-Asadi, 2013, p. 3). The visibility of male and female in When English Rings A Bell VII \& VIII textbooks is shown in the following chart.

Chart 1 reveals that male visibility is more often in illustration than female. Although it is not significant, it occurs in both textbooks. It portrays a tendency toward certain gender to be exposed in such way that conveys meaning more effectively, that is image. The visibility in text, which is less effective in conveying meaning is portrayed more often by female in the first book and male in the second book.

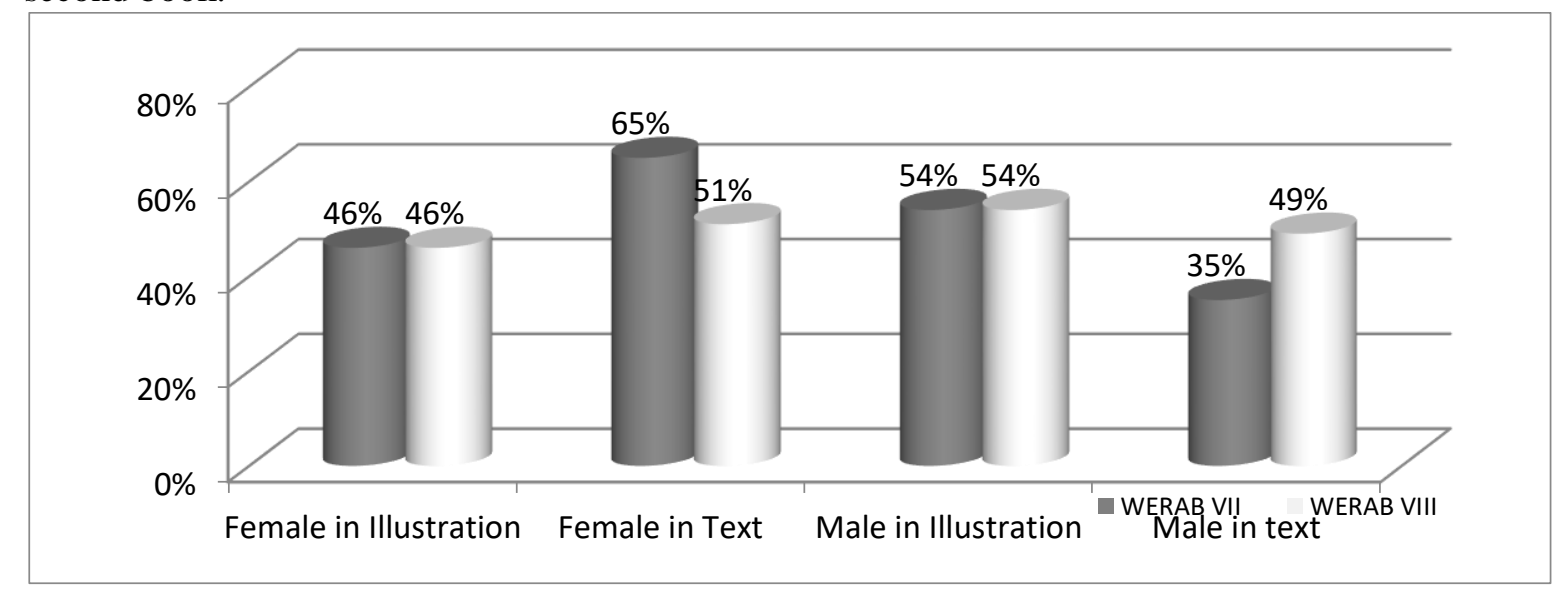

Fig. 1 The Visibility of Male and Female in Werab VII \& VIII 


\section{Gender Firstness}

The second research question was: How is gender characters proportion of being the first in textbook activities? Both textbooks contain a major portion of illustration, thus, the analysis of gender firstness is confined to illustration. The analysis was done in every activity. Every illustration which occurs first in every activity is noted into the observational list and counted to get the percentage. The following is the visualization of gender firstness in the first and second textbook respectively. Based on the result, it is found that females outnumber males of being the first in the first book and the result is reverse in the second book; males outnumber females of being the first. In some parts of the books, males and females are presented in turn. In this way an effort has been made by the writer to put males and females in a balance proportion of being the first represented. It reinforces the equality of males and females. Thus, in terms of gender firtsness, there is no gender bias found.

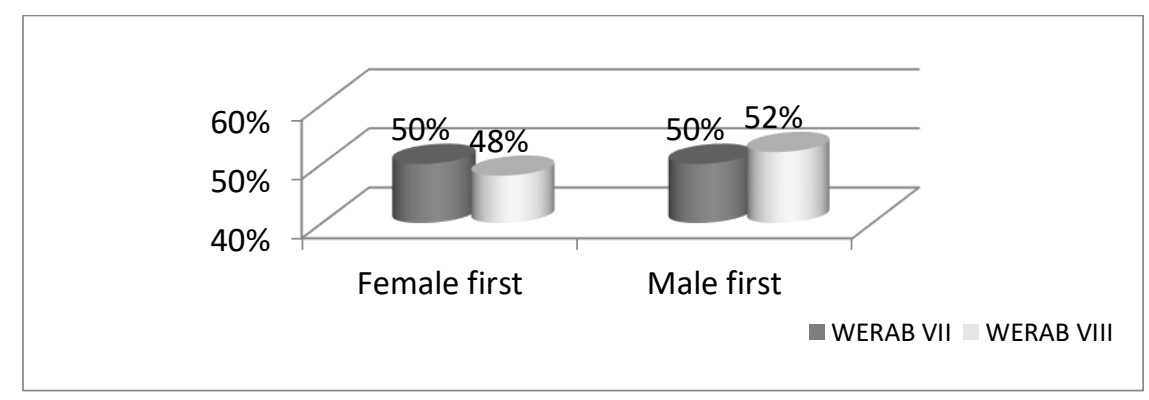

\section{Fig. 2 Gender firstness in Werab VII \& VIIIGender Neutral Noun and Gender Specific Noun}

The third research question was: How are nouns used to refer to male and female? Gender neutral and specific nouns are analyzed with counting, making contrast/comparison, and noting relation between the nouns with other characters. Gender neutral nouns used in WERAB VII are teacher, student, partner, classmate and friend. Gender specific nouns used are identified by noting the relation between the nouns used with other characters.

Generally, both textbooks use more nouns designated to females than males. First book uses 34 (32.1\%) nouns designated to females and $30(28.3 \%)$ nouns designated to males. The rest are gender neutral nouns which cover $42(39.6 \%)$ nouns. Second book uses $232(53 \%)$ nouns designated to females and $176(40.2 \%)$ designated to males. The rest are nouns gender neutral nouns which cover $30(6.8 \%)$.

\section{Occupational Roles}

There are certain jobs assigned only to males and other jobs to females. Generally, the frequency of male and female having professions are almost the same, "WERAB VII" even portrays male and female working in the same amount. But, in "WERAB VII" there are no female portrayed having prestige job as doctor. Doctor is regarded as one of superior jobs (Jin, et al., 2013, p. 119). Ena (2013) who analyzed English e-textbooks used in Indonesia found that certain professions were only represented by men such as doctors, politician, and soldiers. Furthermore, nurse is only designated to female. Renner (1997) asserts that nurse is considered to be a female person skilled in caring for sick people (Mustedanagic, 2010, p. 11). In domestic chores, it is only female who do the laundry, watering the plants, and cleaning the house. Cooking is portrayed only once practiced by male and five time practiced by female. The result reveals that females are generally in charge of caring for people's everyday need; females cook meals, clean homes, and care for children (Eckert \& Ginet, 2003, p. 39).

Masculine Generic Construction

The fifth research question was: What masculine generic construction is used? The analysis reveals that there is no masculine generic construction used in the textbooks. It implies that the use of male noun such he, mankind, his, etc. to refer to both gender is purposely avoided. Instead of using male noun, the writers use she/he or he/she. 
Adjectives used with Females and Males

The sixth research question was: How are adjectives used to portray male and female? From the result, some of adjectives used only for males are energetic and sweaty which imply that males are often take part in outdoor activities. This is conform with a research finding that males are manifested as active and athletic individuals that practice healthy life-styles and they possess the power and energy to take part in abundant outdoor activities (Jin, et al., 2013). Certain adjectives used only for females are patient, beautiful, and sad. The adjective sad portrays that females are emotionally expressive. A study reveals that females are more likely to be characterized as affectionate, emotionally expressive, and passive (Evans \& Davies, 2001).

The result reveals that male are never portrayed display their emotion. In Indonesian society, there is an expression said to a young boy when he is about to cry; "a boy does not cry". Eckert \& Ginet (2003) assert that we think of emotion and desire as natural, but in fact both are highly structured and learned. It is generally said that the taboo against men crying or showing fear requires men to learn to control their emotions.

In reality, males are indeed mostly shown as having more outside activity than females for instance doing sport. Meanwhile, females are often portrayed emotionally expressive, and then is there something wrong with this generalization? Schneider (2004) posits that there is no a priori reason to assume that positive and negative generalizations are fundamentally different except in their consequences. Thus, the data obtained is not judged whether or not it is positive or negative, but rather to reveal the consequences that come after the generalization. In this case, since males are portrayed actively involved in outside activity, while females merely portrayed busy with their emotion, students are drawn to believe that they are as what are portrayed in the textbook they are using. In fact, they do not always experience similar situation often.

\section{CONCLUSION AND SUGGESTION \\ Conclusion}

Based on the analysis, it is found that in certain categories male and female representations is in balance, but in other categories male and female representation still contain gender bias. Gender bias is still found in visibility in which males are portrayed as leader and initiator. A study reveals that women appear largely in material roles, while decision makers and protectors tend to be males (Akpakwu, Simon, Bua, \& Terhile, 2014). In other words, male characters tend to "choose" and "decide" while female characters do not (Sano, Lida, \& Hardy, 2001, p. 902). In terms of gender firstness, the writers of the textbooks concern about gender equality by portraying males and females firstness in the activities. In the first textbook females firstness outnumbers males firstness and in the second book males firstness outnumber females firstness. There is a tendency in WERAB VIII to separate gender relationship. Male nouns are only portrayed to in relation to son and female nouns are only portrayed to in relation to daughter. In this way, students are thought that males only interact with males and females only interact with females. This portrayal can affect students' stand point about relationship.

\section{Suggestion}

Based on the finding, it is suggested that: (a) Educators and parents should be aware of gender bias embedded in many educational materials and texts, and need to combat this bias (Wasseberg, 2008, p. 167) because it narrows the scope of boys' and girls' dreams and limits their life option (Gilbert \& Gilbert, 2002). (b) A teacher can modify the teaching material so that it can give a feeling of being respected for both genders. (c) Gender as a form of classification in the class should be avoided and activities should be so planned that both the genders work together (Narang, 2014).

\section{REFERENCES}

Akpakwu, D., Simon, O., Bua, \& Terhile, F. (2014). Gender Equality in Schools: Implications for the Curriculum, Teaching and Classroom Interaction Journal of Education and Practice, 5(32), $7-14$. 
Cunningsworth, A. (1995). Choosing your coursebook (pp. 90). UK: Macmillan.

Ena, O. T. (2013). Visual analysis of e-textbooks fors senior high school in Indonesia. Doctor, Loyola University Chicago, Illinois. Retrieved from http://ecommonc.luc.edu/luc_diss/513

Evans, L., \& Davies, K. (2001). No sissy boys here: a content analysis of representation of masculinity in elementary school reading textbook. Sex Roles, 42(3).

Fraenkel, J. R., Wallen, N. E., \& Hyun, H. H. (2012) How to design and evaluate research in education (eight ed.). New York: McGraw-Hill Companies.

Gilbert, M. C., \& Gilbert, L. A. (2002). Challenges in Implementing Strategies for Gender - Aware Teaching. Mathematics Teaching in the Middle School, 7(9), 522-527.

Hameed, A. (2014). Language and gender: an analysis of English textbooks produced by punjab textbooks board for elementary level in pakistan. Journal of Education and Practice, 5(11).

Hamid, B. D. H. A., Yasin, M. S. M., Bakar, K. A., Keong, Y. C., \& Jalaludin, A. (2008). Linguistic sexism and gender role stereotyping in Malaysian English language textbooks. GEMA Online Journal of Language Studies, 8(2).

Jin, N. Y., Ling, Y. C., Tong, C. S., Ling, L. Y., \& Tarmizi, M. A. A. (2013). An analysis on genderbased language and ilustration in Malaysian secondary schools' language and literature textbook. International Journal of Humanities and Social Science, 3(18).

Littlejohn, A. (1998). The analysis of language teaching materials: inside the trojan horse. In B. Tomlinson (Ed.), Materials development in language teching (Vol. second). UK: Cambridge University Press.

Mayring, P. (2000). Qalitative content analysis. Forum Qualitative Social Research, 1(2).

Miles, M. B., \& Huberman, A. M. (1994). Qualitative data analysis (second ed.). USA: Sage.

Mustedanagic, A. (2010). Gender in English language and EFL textbook. master, Halmstad University, Sweden.

Narang, N. (2014). Exploring Gender Relations in The Context of School Practices. IMPACT: International Journal of Research in Humanities, Art, and Literature, 2(2), 73-82.

Porecca, K. L. (1984). Sexism in current ESL textbook. Tesol Quarterly, 18(4), 705-724.

Renner, C. E. (1997). Women are "busy, tall, and beautiful": looking at sexism in EFL material: University of Naples.

Sano, F., Lida, M., \& Hardy, T. (2001). Gender Representation in Japanese EFL Textbook. Paper presented at the PAC3 at JALT 2001 conference Proceeding, Japan.

Sardjunani, N. (2013). Gender Equality in Education in Indonesia: ACDP Indonesia: Education Sector Analytical and Capacity Development Partnership.

Schneider, D. J. (2004). The psychology of stereotyping. New York: Guilford Press.

Slater, L. M. (2003). Gender Bias in Elementary Schools: An Examination of Teacher Attitudes. Undergraduate Thesis, Miami University, Ohio. 